\title{
Action Research to Improve Students' Problem-Solving Skills using Social Cognitive Theory and Problem based Learning Strategies
}

\author{
Thaier Hamid, PhD \\ The University of Bolton \\ Deane Rd, Bolton \\ BL3 5AB, United Kingdom
}

\author{
Francis Morrissey \\ The University of Bolton \\ Deane Rd, Bolton \\ BL3 5AB, United Kingdom
}

\author{
Abdul Razak \\ The University of Bolton \\ Deane Rd, Bolton \\ BL3 5AB, United Kingdom
}

\begin{abstract}
The main aim of this action research is to improve the student's technical problem-solving skill to fix and manage different technical problems in higher education Institutes. One of the main reasons for the deterioration of higher education institutions in providing the labour market with qualified professional cadres is keeping academic curricula in the classical frameworks and not develop the curricula to coincide with the technical progress. Solving technical problems has become an urgent need of the majority of the commercial companies, due to the expanded use of computer technologies and networks, for example, a single technical problem that disrupted the work for an hour may cost the businesses hundreds of millions of pounds. The implementation of this action research done in two different stages, the first and second stage to implement during the study and the third stage will perform in the future. The first stage strategy to achieve the Social Cognitive Theory (SCT), The second stage to implement the Problem Based Learning (PBL) using Guided practice strategies. Simple questioners were given to the learners, before and after the formative or summative assignments or the class problems solving activities. The results of questionnaires were analyzed in detail to determine the actual impact of different strategies applied to enhance problem-solving skills. In this research, we have been able to reach satisfactory results to improve the level of students in technical problem-solving skills this required significant efforts and times using PBL, Guided practice tutorials to help the learners mastering the problemsolving techniques. Because of the time limitation of this action research, the third stage of using PBL with application strategy to reduce the amount of the efforts and times will be implemented in future research.
\end{abstract}

\section{General Terms}

Networking Security Management System, learning strategies, Teaching and learning in the higher education institutes.

\section{Keywords}

Social Cognitive Theory, Problem Based Learning, learning strategies.

\section{INTRODUCTION}

This Action research focuses on the improvement of the student's problem-solving skills in the department of Networking and security, University of Bolton. The ability to solve computer networks problems is one of the essential skills that qualify students to acquire technical jobs. While the labour market is in dire need of highly skilled technicians in diagnosing network problems and finding solutions in high quality and in record time. The problems solving skill is critical for the networking and security students, as much of our student's future accomplishment will measure their abilities to fix different networking problems caused by incorrect configurations or due to the security breaches and hacking. The time dedicated to repairing a specific problem in the networking caused by improper setting or due to the malicious attacks will reflect on the success of the students to perform and act in the future as professional technicians in this field. Therefore, all students in the department need to enhance their skills in problems solving.

1.1 Social Cognitive Theory (SCT): SCT defines learning as a function of internal connected factors, the behavioural and the cognitive and the environmental influences [3]. Social cognitive, using Collaborative teaching and learning tool such as peer-based and simulation learning which could include technical problem-solving activities in the shape of simple scenarios. The four essential observational items of SCT are the process of symbolic coding, Intrinsic and extrinsic motivations, motor retention progressions and concentration [2]. Using SCT as a framework to enhance the student's problem-solving skills by design and construct simulated learning activities and then measured the students' reactions by observations, questioner results, characterize the first stage of our action research. Thus, in parliamentary procedure to minimize risks, the study comes out with a model of keyfactors, but, firstly the authors considered on a related work which explained the background of the study.

1.2 Problem Based Learning (PBL) strategies: Problembased Learning (PBL) is an active learner-centred pedagogy. The students learn the different topics related to the specializations through common professional problems associated with the Future issues that students will face in the field of work. PBL approach is more complicated than social cognitive-based strategies as the PBL strategies focus mainly to improve the general problem-solving techniques or produce located professional practice as in Predict-Observe-Explain (POE) techniques referenced by [25]. Current studies stressed that the best methods to solve the problems by dividing the problems to small individual fragments and provide instructions to deal with these fragments to enhance the problem-solving skills for students [14]. The specific problem-solving training could help the students to progress toward understanding and solving the problems compared with other learners who never got the problem-solving training [11]. In the second phase of this action research, we assimilated the SCT with PBL strategies, to provide the students with the simulated scenario with enough instructions 
to solve the fragmented problems and perceived the results by the observations and the questioner results.

\section{STATEMENT OF THE PROBLEMS}

During the observations and the self-reflection of the teaching in the networking and security department, the authors witnessed (according to the classes observation and students result in analyses) that the students are facing difficulties to stretch to the right solution for different technical problems.

Most of the students $(60 \%)$ achieved underneath the standard, and $20 \%$ performed under unacceptable performance.

This action research tries to find some answer to the following issues:

1- Why the students facing difficulties to comprehend the grounds of the problem?

2- The leading cause that the learners failed to find suitable resources to sort out the problems.

3- Reasons for the students' difficulties to catch the correct procedure to fix the problems and generate solutions?

4- Explanations for learners' difficulties to touch to the right fragment (process) that caused the problem?

5- Why the students make a lot of mistakes and errors that cause the problem more complicated?

\section{THE CONCEPTUAL FRAMEWORK}

The conceptual framework of this research designed to shield the following three parts:

1- Train the students to effectivity using the standard technical materials and procedures to develop their skills in troubleshooting and problem-solving. Such as creating separate broadcasting domains using Router to avoid the impacts of the problems to transfer to the entire network and to fragments the area of the troubleshooting to make the troubleshooting area small enough to find the issues. Train the students to use the troubleshooting commands effectively, such as ICMP commands. using the Simple Network Management Protocol (SNMP) to monitor the functionality of the network, computing devices, and checking the protocols anomalies such as the TCP handshaking and traffic patterns to find out if the problem caused by hacking activities.

2-Decide on the right phase of teaching and learning strategies.

We studied the different phases of the PBL teaching and learning strategies. Modelling phase in which the lecturer demonstrates to the students the correct behaviour and methods for problems solving; Guided practice phase in which the students work in a group to identify the issues, solutions and act according to the supervision of the lecturers. Application phase: In this phase, the students work in a group, and the learning process and problem-solving take place as interactions and exchange of the information and skills between the learners, independent of the lecturers. Many of researches spectacled that the Guided practice could represent practical approaches in endorsing learning [1]. The Guided practice strategy is more suitable to use in stage -2 of our research as most of the students facing difficulties in problemsolving and the interference of the lecturers needed in this stage of action research.
3-Using problem-solving group assignments with a simple survey before and post the activities. Formulating several formative and summative problem-solving tasks to provide the following advantages:

a) The students exchange their experience and skills in different topics and problems solving techniques. For example, in one of the small groups working with an assignment, the students failed to use the troubleshooting tools to find the sources of the problem, with the help of students-2 (which he was outstanding in using the networking monitor software utilities (SNMP)).

The source of the problem founded, and suitable solution applied, both learners scored high marks and gaining the same skill set using networking monitor tools.

b) The students can do the different tasks of the assignment in their free and outside the working hours.

c) The students will have enough time to refer to the standards and technical documents to complete the assignments tasks.

To evaluate the students' performance, a matrix of criteria has developed as follows: the ability of the learner to find the problems and decide the requirements to fix them using appropriate procedures to reach to the solutions. And document the methods of finding the issues and the steps to implement the solutions to use these documents for future references.

The level of achievement classified as follows:

Above the standard: when the students find the problems and implement the solutions in the innovated way. And in the typical time and document the finding as rigours procedures.

Meet the standards: when the students used the technical documents and the procedure to find the problem and the countermeasures at the right time with an appropriate level of documentation

Below the standard: when students find the problem and try different solutions. But none of the solutions stops the cause of the problem and the documentation underneath the criteria. Unacceptable: when the students failed to find the issues and the solutions.

\section{BACKGROUND STUDIES}

Social cognitive, using Collaborative teaching and learning such as peer-based and simulation learning which could include technical problem-solving activities in the shape of simple scenarios. The assistance of implementing the SCT, which used by forming the learners to a group, to exchange the knowledge and skills and the experience studied by several authors such as [5] [8]. The four critical observational items of SCT are the process of symbolic coding, Intrinsic and extrinsic motivations, motor retention progressions and concentration [2]. The Mainstream for the researches in the area of the Problem Based Learning (PBL) considers the PBL strategies as part of the cognitive $\mathrm{c}$ When the students deal with a specific problem, they recall the past knowledge and integrate it with new information gathered around the challenge to understand and fix the problem. This will result in constructing a new understanding (refined the prior knowledge), this knowledge will be developed further with the contribution of a small group of learners by exchanging the knowledge and the experience to create a mental model representing the structure of the problems and the causes [7]. The students using the PBL approach. They custom the current mental model and related resources to improve the 
projected solutions, and this enables them to identify the gaps in their prior knowledge and help them to use different resources to fill these gaps and enhance the problem-solving approaches. Using the PBL strategies could be considered as the best learning approach in the field of the problem solving, enabling the learners to develop their knowledge and create a mental model suitable to be translated as a procedure to solve different problems [9]. Constructivist framework [19]. Much of the researches on SCT and PBL focused around the specifications of the problems. Used in education to cause effective learning and knowledge improvements in the interpretation of the learners and the lecturers. [12] [13] [21] Theses researches presented the specifications of the problem, which can cause active learning as a problem should be:

\section{a) Accurate;}

b) be relevant to the learner's level and companionable with past knowledge;

c) the problem scenario should encourage in-depth discussions among the learners and with the lecturers;

d) The problem should lead to an appropriate solution and cause active learning and added values to prior knowledge.

In the research paper of Dolmans [6] the influence of the PBL strategies on the students learning analyzed by benchmarking the consequence of identifying the problems issues on the learning by selecting a topic related to a particular discipline, using student's questionnaire and through statistical analyses of questionnaire inputs. The results showed that $63 \%$ of active learning happened when the students identified and fully understood the cause of the problems. The other types of knowledge occurred when the lecturers or the tutors present or help in the process of identifying the issues. The students' familiarity with problems and the influence on practical learning and knowledge in the PBL has studied in the research papers of [20] and [18] by presented a challenge to the students classified in a small group of learners to several groups familiar with the problem and a other groups not familiar with the problem. A set-up of criteria created to quantify the observed problem value. The inferiority of the clarifications related to the problem given to the learners; the number of queries related to the problem; the quality of discussion inside the members of the group; the time spends to understand and fix the problem; the value of the knowledge and learning gained (through a short test); The results show that the groups of students familiar with problem received a high quality of learning compared with other groups, which are not familiar with the problem. The results highlight on the importance of the problem-solving strategies implementations to our students in the networking and security departments to get them familiar with the standard types of the problems in the workplace to create a quality of graduates in this field. In PBL strategies, many types of problems used such as learners' conceptual knowledge of a specific subject problem (such as mathematics or physics) or the qualitative and quantitative problems and experiments challenges. The experiments problems type developed by Van Heuvelen, 1995, he designed many laboratory problems similar to workplace problems, to get the learners familiar with different kinds of the issues that might be faced after graduation. [23]. The benefit of small peer tutorial (Guided practice tutorial) is to motive the students to achieve their goals and to meet the deadlines assigned to the learners during the PBL strategic implementations. [24]

\section{5. .ACTIONS RESEARCH IMPLEMENTATION}

The application of this action research done in two different stages, the first and second stage implemented during the study and the third stage will perform in the future. The first stage strategy to achieve the SCT, to the HE6 students studying the network security and ethical hacking and network management modules. The justifications for selecting final year students. As we mentioned in the background studies, regarding the design and specifications of the problems "the problems should be relevant to the learner's level and companionable with the past knowledge;" The second stage to implement the PBL with Guided practice strategies using small peer tutorials and according to the recent researches in this field. In the third stage, we will implement PBL with application strategies, the learners work in a small group, and the learning process occurs as a result of exchanging process of the information and skills between the learners, independent of the lecturers. As shown in appendix 1 , the simple questioners were given to processed by the learners, before and after the formative or summative assignments or during the class problems solving activities. As we explained in The Conceptual Framework section, the due diligent used to design the questions and used in the issues sceneries to be suitable to the student's prior knowledge and skills. We created many networking problems caused by wrong setting or fault in the networking or computing devices, like real-time problems and insert the problems scenarios in the form of class practical exercises formative or summative assignments. The observations used to evaluate the students' performance in problems solving process

\subsection{Action-1: Implement SCT, small group problem} solving

The small problem-solving group's strategies are used in the first stage of this action research to develop the students learning and knowledge in the technical solving issues through the discussions and exchanging the skills and experience.

The students divided into small groups with care and diligent according to the students' grades in different networking and security modules. The technical skills and experience with the considerations of the ethnic background and other demographic factors. With confirming that each group has a variety of students with a different set of skills.

The small groups designed to solve the problems using SCT with the following setting:

1- The students should get enough practice in the networking topics related to the problem they deal with before starting the group activities to solve the issues.

2- When the learners disagree of a specific issue related to the problem or the solutions, they should exclusively discuss it inside the group and try to find the appropriate agreements before escalating it to the lecturers.

3- The problems solutions tasks should be distributed equally between the small group members, and each member must participate in the problem solutions activities by providing a new set of skills and experience in the topics related to the problem.

4- The members of the small group should reveal the 
lack of understanding of the topics related to the problems to allow other members to help in term of learning from others.

5- Encouraged the learners to use Metacognitive strategies during and after the problem-solving activities. (some training were given to the students on the self-reflecting and feedback given to the students during observations about their performance to develop their problem-solving skills). This process includes recognizing the softness and the strength of the problem's solver.

6- Encourage the learners to use multiple solutions for single problems by instructing the students to see the problem from different perspectives.

After submitting the first problem-solving assignment, to the small groups, a brief of the task was given to the students with questions and answers session, and then they asked to fill short questioner.

The result of the pre-implementing of the SCT shown in figure-1.

As you can see in the first question, we asked the students about their knowledge level of the problem projected.

We used the Likert scale-4 to analyses the results, which show that $60 \%$ of the learners understand the problem.

To critically reflect on this result; the authors believed that the majority of the students answered this question to replicate on their understanding of the assignment brief. They do not reflect on their abilities to recall the prior knowledge and use the current information to understand and fix the problem as in this stage the students have not started their effort to understand and fix the problem. In question-2, we asked the students the degree of difficulties that they think will face with solving the proposed issue; the results showed that $65 \%$ of the students they believe they will face some problems. The authors conclude that the main reason for this result is the students' unfamiliarity with the problem and the lack of confidence and skills to fix the issues.

The result analysis of question-3, regarding the selfconfidence on students' abilities to fix the problem, showed that $60 \%$ of students responded negatively because of the lack of the skills, familiarity and confidence. In the question-4, which we asked the students about the degree of competence on the topics of the problem. $55 \%$ of the students showed a low degree of skill. The authors trust that the learners pointed to critical point related to their ability to use the troubleshooting and networking monitor tools, which we will deal with it in the stage- 2 of this action research. $90 \%$ of the students read the problem statement prudently, and they are highly motivated and understand the importance of problemsolving skills. This because the lecturer explained the problem in detail in the assignment brief, and stress on the importance of the problem-solving skills in the workplace. See Fig 1.
Student Questionnaire Results-Beforehand Social cognitive theory implementations.

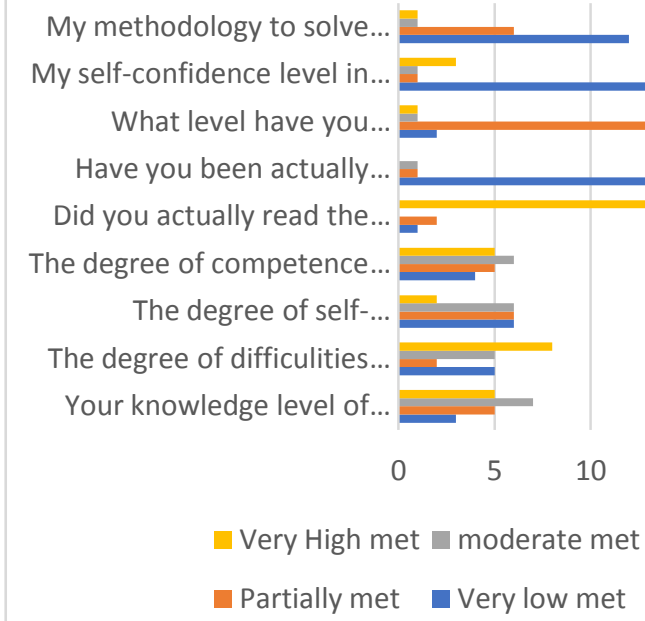

$\begin{array}{lll}0 & 5 & 10\end{array}$

Very High met $\square$ moderate met

- Partially met $\quad$ Very low met

Fig 1 Student Questionnaire Results -Beforehand Social cognitive theory implementations.

In another side, $25 \%$ of the learners, they need to improve their knowledge after completing the assignments; this highlights the need to implement other strategies. Another interesting response in this survey, when the students answered the question of the degree of the difficulties they faced during dealing with the problem and the try to find the appropriate solution. As $60 \%$ of the students thinking that they will face some issues during dealing with the question before the implementations, after the execution, this percentage increased $5 \%$ to reach $65 \%$. The increment of the difficulties dealing with the problem because the students during the implementations practically faced the problem and they have a hand of experience dealing with problem-solving techniques, although the percentage before the implementations represent their opinion according to the assignment brief. $55 \%$ of the students successfully fix the problem according to the assignment deadlines. In my opinion, these results highlight the needs and the importance of PBL strategies to provide the students with the information and skills to deal with the troubleshooting tools and network monitoring commands using guided practice strategies. The degree of self-confidence increased from $40 \%$ to $55 \%$ and the degree of competence in the topic of the problem enhanced from $55 \%$ to $65 \%$. We believed that this improvement due to the implementation of SCT strategy, and again this results not good enough to improve our teaching and learning, other plans need to use to strengthen most students' skills in a problem-solving. Another impressive result in this survey related to the question about the student's interest in observing and probing the process of problem-solving. The results jump from $5 \%$ to $50 \%$; the authors believed that this one of the impacts of SCT implementations, as the students observed each other trying to solve the problem during the application which caused that the learners were observing and probing their abilities and knowledge. The following equation was used with the results derived from Likert scale-4 to calculate the level of sophistication in problem-solving skill in this stage:

$$
\bar{x}=\frac{1}{n} \cdot \sum_{x=1}^{n} a_{x}
$$

$\mathrm{n}$ represents the number of the students' response in the 
survey, and 'a' represents the number of positive responded.

$$
\bar{x}_{1}=43
$$

before the implementation.

$$
\bar{x}_{2}=61.5
$$

after the implementation of stage 1 .

the following equation used to calculate the adequate progress in students' problem-solving skill:

$$
x_{e}=\bar{x}_{2}-\bar{x}_{1}
$$

$$
x_{e}=18.5
$$

The adequate progress in the student's problem-solving skills using SCT is $18.5 \%$.

\section{RESULTS-AFTER SOCIAL COGNITIVE THEORY IMPLEMENTATIONS.}

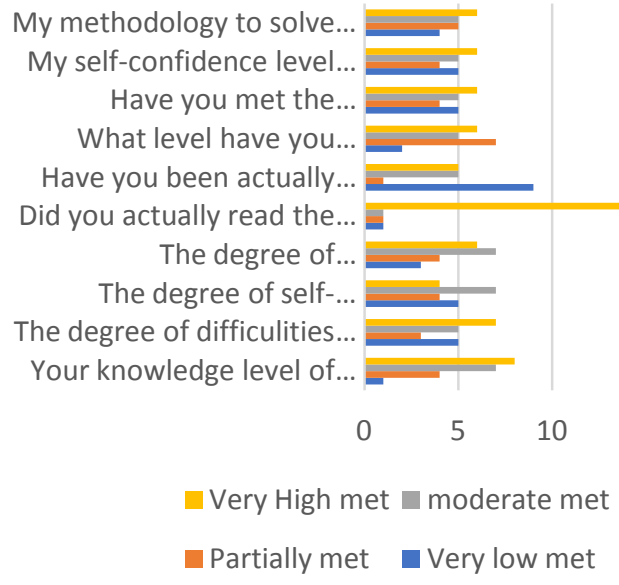

\section{Very High met $\square$ moderate met}

- Partially met

Very low met

Fig 2 A Student Questionnaire results-afterward Social cognitive theory implementations.

\subsection{Action-2: Implement PBL strategies}

According to the results and observation of the outcomes of stage-1, and to improve the student's problems solving skills, we need to highlight the main issues related to the slight improvement of the problem-solving skills during the SCT implementations.

1- The learners need in-depth knowledge using the troubleshooting and diagnostics tools to enable them to find and define the problems.

2- The students need more training analyzing the problems, to find the cause of the issues to formulate options of solutions.

3- The students need some training in the process of evaluating the solutions. And measure the impacts on the performance of the network and to the security policies and procedures.

4- The students need more training and help in the process of implementing the problem solutions using appropriate tools, to measure the impact of the implementation on the network performance, the effect of the answers on other services running on the network and evaluate the impact of the solution on the network security.
To fill these gaps in SCT implementation, the PBL strategies selected to improve the student's problem-solving skills successfully. As discussed in the Conceptual Framework, we divided the students to small groups; these groups should have guided tutorial sessions supervised by the lecturer before starting the problem-solving activities. In these guided tutorial sessions, the students provided with technical documents related to effective use of the troubleshooting and diagnostics tools, network monitoring and services utilities.

In these sessions, the lecturer provided some similar alternative problems to the main problem in the assignment. to train the students to the systematic way of solving the issues.

The tutorials focused on the following areas:

1- Trained the learners to use effectively the troubleshooting and diagnostics tools such as scanning, monitoring and sniffing tools to help the students to find and define the problems;

2- Trained the students to use sniffing tools such as Wireshark to thoroughly analyzed and understand the cause of the problem to find alternative solutions;

3- Trained the students on how to use the results of different tools with in-depth discussions and researches to evaluate the impact of different solutions on the network performance, other services running on the network and evaluate the impact of the solutions on the network security;

4- The students are trained, working as a team to make a final decision on the selected solutions. And educate the learners on their responsibilities on the consequences of that decision.

5- Trained the students on different methodologies of solutions implementation and monitoring the network for any secondary problems that might happen and check the logs and various monitoring tools for the normality of the operations.

Then a problem submitted to the learners and the surveys were taken to monitor the impact of the PBL strategies on the student's problem-solving skills.

RESULTS-AFTER PBL STRATEGIES IMPLEMENTATIONS.

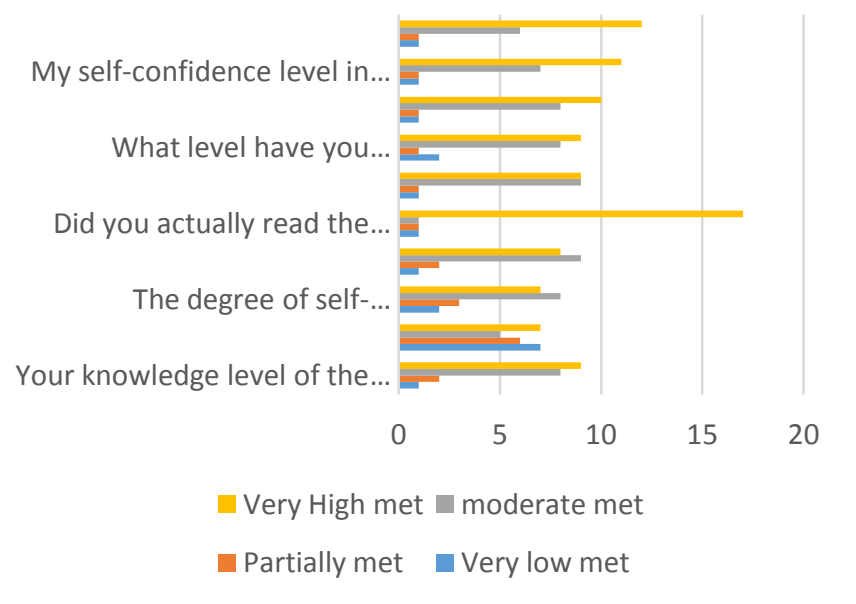

Fig 3 Student Questionnaire results-After PBL Strategies implementations. 
Figure-3 shows the result analysis after the PBL implementations, the knowledge level of the projected problem improved $10 \%$, as $85 \%$ of the students believed that they have better understanding and knowledge about the projected problem. In question-2, we asked the students the degree of difficulties that they think will face with solving the proposed problem, and the results showed only $25 \%$ of the students they think they faced some difficulties. In comparison, $75 \%$ of the students confronted faced low difficulties. The self-confidence in question 3 improved to $75 \%$ and the question- 4 regarding the degree of competence on the topics of the problem, $85 \%$ of the students showed a high degree of competence. In the question related to the interest of observing and assessing the processes of problemsolving, $90 \%$ responded positivity to this question as the tutorial's sessions stressed on observing the problem-solving thinking. The student responded to the question "What level have you achieve on this task?" As $85 \%$ of them achieving the task successfully. $90 \%$ of the students met the deadline and the self-confidence and the methodologies in solving the problem reach to $90 \%$.

$\bar{x}=\frac{1}{n} \cdot \sum_{x=1}^{n} a_{x} ; \mathrm{x}_{2}=61.5 ; \mathrm{x}_{3}=82.5$

$\mathrm{X} 2$ before the stage- 2 implementation

X3 after the implementation of stage 2 .

The equation (2) used to calculate sufficient progress in students' problem-solving skills.

\section{$\mathbf{X}_{\mathrm{e}}=\mathbf{X}_{\mathbf{3}^{-}} \mathbf{X}_{\mathbf{2}}$}

$X_{\mathrm{e}}=\mathbf{2 4}$.

The possible improvement caused by using PBL with the guided tutorial's sessions is $24 \%$. Because of the time limitation of this action research, the PBL with application strategy will be implemented in future research.

\section{PROBLEM-SOLVING SKILLS AND CURRICULUM DEVELOPMENT}

To help our students to have the skills and the competencies in the networking problem-solving. To secure a job in the future and become an expert in this field. The perspective of the problem solving should exceed current curricula. The learners should have proper skills not only in identifying the different issues but also finding robust alternative solutions. To various networking and security problems, using the problem-solving strategies as a critical component, in the teaching and learning of the networking and security modules, the clarification of the connections between the computer networking and security knowledge and the problem-solving strategies components must be incorporated in the curriculum development. For example, to enable the students in the final year of computer networking and security departments to master networking problem-solving. These students should study the effective use of troubleshooting, diagnostics and sniffing tools in the first year, and the learner's practice through the problem-solving routines in the second year. When the associations between these mechanisms become clear enough, we can set the instructions to enable the students to use the problem-solving to enhance the computer networking and security components. The problem-solving techniques must be treated as an essential part of developing the understanding of networking and security topics. That is mean when the lecturer covers the essential networking topics, the issues should be presented as a problem, and the students will understand the subject and related setting and configurations using PBL strategies. The effective problemsolving curricula enable the learners to go beyond their experimental behaviours in finding the problem and the solutions.

\section{OVERALL CONCLUSIONS AND FUTURE WORKS}

In this action research, the SCT and PBL strategies used to enhance the student's problem-solving skills. By improving the learners understanding of the types and the sources of different problems and the ability to implement appropriate solutions.

Guided group tutorials used to train the students, on how effectively use the troubleshooting tools to discover the cause of the problems, sniffing tools, network monitoring applications to monitor the traffic, finding attacks and countermeasures implementations on the network performance and other services. Appropriate procedures, presented to the students to train them, discovering the problems and find appropriate solutions using problem fragmentation approaches. Proper training was given to the learners to document different problem-solving strategies and using the most useful approached to enhance the procedures. The tutorials sessions covered different approaches to reduce the number of errors that might originate during the problemsolving operations to avoid any complications on the original problems, which might make the problem solving impossible. One of the essential findings derived from the group's observation and analysis of the results, that the main reason behind the poor performance of students in the problemsolving process due to the lack in the ability to use troubleshooting tools and network monitoring utilities and the lack of experience in dealing with such problems. The other reason for the inability of students to use and develop the technical procedures in the problems solving is the lack of the training programs to document different ways of discovering and solving problems to return to those documents when the various technical issues occurred.

Regarding the difficulties that the learners demonstrated in finding the central part that causes the problems. The author believes that the lack of comprehensive technical understanding and assimilation of relationships to interrelated technical processes is one of the essential difficulties that we have tried to solve and have incorporated into educational strategies. As the students worked in groups to exchange expertise, in addition to the guided tutorial's sessions, the students successfully improved their problem-solving skills and documentation.

The implementation of the problem-solving strategies has contributed to raising the efficiency of students in this area.

After the implementation of the SCT according to the results of the questionnaire and the observations of the workgroups, modest progress occurred in the skills of students in the process of solving technical problems $(18.5 \%$,) which necessitated to implement other strategies to bring the required development. The second stage to achieve the PBL with Guided practice strategies using small peer tutorials and according to the recent researches in this field. Simple questioners were given to the learners, before and after the summative problems solving assignments. The possible improvement caused by using PBL with the guided tutorial's sessions is $24 \%$ comparing with SCT. We have been able to reach satisfactory results to improve the level of students in 
technical problem-solving skills to meet the standards of technical problem-solving, according to the result analysis and observations, the student's skills improved to $42.5 \%$ since we started this research. Problem Based Learning (PBL) using Guided practice strategies processes required excessive efforts and times to help the learners mastering the problem-solving techniques. Because of the time limitation of this action research, the third stage of using PBL with application strategy to reduce the amount of the efforts and times in the process of developing the student's problem-solving skills will be implemented in future research

\section{REFERENCES}

[1] Aggarwal, J.C., 2009. Principles, methods \& techniques of teaching. Vikas Publishing House.

[2] Bandura, A., 2001. Social cognitive theory: An agentic perspective. Annual review of psychology, 52(1), pp.126.

[3] Burke, H. and Mancuso, L., 2012. Social cognitive theory, metacognition, and simulation learning in $\mathrm{n}$ Bandura, A., 2001. Social cognitive theory: An agentic perspective. Annual review of psychology, 52(1), pp.126. Nursing education. Journal of Nursing Education, 51(10), pp.543-548.

[4] Colliver, J.A., 2000. Effectiveness of problem-based learning curricula: research and theory. Academic medicine, 75(3), pp.259-266.

[5] Dodell-Feder, D., Ressler, K.J. and Germine, L.T., 2019. Social cognition or social class and culture? On the interpretation of differences in social cognitive performance. Psychological medicine, pp.1-13.

[6] Dolmans, D.H., Snellen-Blending, H. and van der Vleuten, C.P., 1997. Seven principles of effective case design for a problem-based curriculum. Medical Teacher, 19(3), pp.185-189.

[7] Ellis, M., 2019, February. Computer Science Problem Solving Course: Practical and Technical Thinking Skills for CS Majors. In Proceedings of the 50th ACM Technical Symposium on Computer Science Education (pp. 1267-1267). ACM.

[8] Fawcett, L.M. and Garton, A.F., 2005. The effect of peer collaboration on children's problem- solving ability. British Journal of Educational Psychology, 75(2), pp.157-169.

[9] Hmelo-Silver, C.E., 2004. Problem-based learning: What and how do students learn?. Educational psychology review, 16(3), pp.235-266.

[10] Huang, T.C., Huang, Y.M. and Yu, F.Y., 2011. Cooperative weblog learning in higher education: Its facilitating effects on social interaction, time lag, and cognitive load. Journal of educational technology \& society, 14(1), pp.95-106.

[11] Huffman, D., 1997. Effect of explicit problem-solving instruction on high school students' problem- solving performance and conceptual understanding of physics. Journal of Research in Science Teaching: The Official Journal of the National Association for Research in Science Teaching, 34(6), pp.551-570.

[12] Jacobs, A.E., Dolmans, D.H., Wolfhagen, I.H. and Scherpbier, A.J., 2003. Validation of a short questionnaire to assess the degree of complexity and structuredness of PBL problems. Medical education, 37(11), pp.1001-100

[13] Kim, S., Phillips, W.R., Pinsky, L., Brock, D., Phillips, K. and Keary, J., 2006. A conceptual framework for developing teaching cases: a review and synthesis of the literature across disciplines. Medical education, 40(9), pp.867-876.

[14] Kim, Y.J., 2019. Observational Application Comparing Problem-Based Learning with the Conventional Teaching Method for Clinical Acupuncture Education. Evidence-Based Complementary and Alternative Medicine, 2019.

[15] Mingus, T. and Grassl, R., 1997. Using technology to enhance problem-solving and critical thinking skills. Mathematics and Computer Education, 31(3), pp.293300 .

[16] Norman, G.R. and Schmidt, H.G., 2000. Effectiveness of problem- based learning curricula: Theory, practice and paper darts. Medical education, 34(9), pp.721-728.

[17] Rath, M., 2019. Information Security Problem and Solution Approaches in Social Applications. In CyberPhysical Systems for Social Applications (pp. 207-220). IGI Glob

[18] Schmidt, H.G., Rotgans, J.I. and Yew, E.H., 2011. The process of problem- based learning: what works and why. Medical education, 45(8), pp.792-806.

[19] Schmidt, H.G., Van der Molen, H.T., Te Winkel, W.W. and Wijnen, W.H., 2009. Constructivist, problem-based learning does work: A meta-analysis of curricular comparisons involving a single medical school. Educational Psychologist, 44(4), pp.227-249.

[20] Sockalingam, N., Rotgans, J. and Schmidt, H., 2012. Assessing the Quality of Problems in Problem-Based Learning. International Journal of Teaching and Learning in Higher Education, 24(1), pp.43-5

[21] Sockalingam, N., Rotgans, J. and Schmidt, H.G., 2011. Student and tutor perceptions on attributes of effective problems in problem-based learning. Higher Education, 62(1), pp.1-16.

[22] Wu, F. and Chen, Z., 2019, March. The Actuarial and Simulation of Learning Strategies under Japan's University Education. In 2018 8th International Conference on Education and Management (ICEM 2018). Atlantis Press.

[23] Yuliati, L. and Ni'mah, B.Q.A., 2019, February. The influence of PBL-STEM on students' problem-solving skills in the topic of optical instruments. In Journal of Physics: Conference Series (Vol. 1171, No. 1, p. 012013). IOP Publishing.

[24] Zander, L., Brouwer, J., Jansen, E., Crayen, C. and Hannover, B., 2018. Academic self-efficacy, growth mindsets, and university students' integration in academic and social support networks. Learning and Individual Differences, 62, pp.98-107.

[25] Zarei, E., Shokrpour, N., Nasiri, E. and Kafipour, R., 2012. Self-Esteem and Academic Success as Influenced by Reading Strategies. English Language Teaching, 5(2), pp.17-26. 